\title{
Leadership in Education During COVID-19: Learning and Growth through a Crisis
}

\author{
LINDY HUDSON $^{1}$, SESHAANTH MAHENDRARAJAH ${ }^{1}$, \\ MARTINA WALTON ${ }^{1}$, MICHAEL PASCARIS ${ }^{1}$, SONYA MELIM ${ }^{1}$ AND \\ ROBYN RUTTENBERG-ROZEN ${ }^{1}$ \\ ${ }^{1}$ University of Ontario Institute of Technology
}

\begin{abstract}
This article explores themes resulting from a group autoethnography conducted during the COVID-19 pandemic. As participants, we are education graduate students and a professor working in both formal and informal leadership roles. We met twice a week to reflect on our present experiences implementing and leading distance education during the COVID-19 pandemic and to use these reflections to (re) imagine the future alignment of technology and education. Our self-reflexive discussions uncovered common experiential themes around educator agency, technology induced anxiety, and leadership agency. We highlight our own growth through reflection, and we suggest important leadership qualities during times of pandemics that will raise the level of motivation and engagement of school communities and have the potential to create a stronger individual and institutional sense of agency and resiliency during a time of crisis.
\end{abstract}

Keywords: Collaborative autoethnography, pandemic, educational leadership, technology, reflection, agency

\section{INTRODUCTION}

\footnotetext{
I $\mathrm{n}$ the early spring of 2020, the emergence of COVID-19 prompted unprecedented closures of schools and businesses across Canada and the US. As the crisis continued, educational leaders (EL) from all areas of education had to pivot their practice overnight in order to develop distance learning and provide support to their teams. This pivot required a shift from other priorities to a hyper-focus on technology implementation. Due to the pandemic requirements for distance learning, the crisis involved a great deal of focus on the rapid implementation of technology to support learning and working from home. Leaders were tasked with a complicated undertaking while supporting their teams
} 
because not all educators have the same level of comfort or expertise with the integration of technology into their practice (Anthony, 2011; Fawns et al., 2020). Technology-based learning takes time to develop and implement, and the imminent need for distance learning was challenging for those who previously did not use technology at the point of instruction (Fawns et al., 2020). Leaders in education needed to support this implementation by providing assistance to their teams of people with various abilities and readiness for technology (Breitkopf, 2018; Hung, 2015; Naidu \& Laxman, 2019; Yuen \& Ma, 2008). We view leadership as "a process whereby an individual influences a group of individuals to achieve a common goal" (Northouse, 2019, p.5), with a focus on group processes and personality perspectives including traits and behaviors (Bass, 2008). Leadership includes both assigned leaders, who hold formal leadership positions within an organization as well as emergent leaders, who do not hold formal leadership roles but are influential to group or organizational members and of whom group members are accepting of this influence (Northouse, 2019).

Educational leadership has always been important to support technology integration in educational contexts (Leithwood et al., 2019). However, we know little of educational leadership practices that support technology during crisis situations. There is still much to be learned about the intricate interplay between technology, leadership, implementation, and crisis. In this paper we describe the results of a collaborative autoethnographic study by educational leaders - including $\mathrm{K}-12$, postsecondary and postgraduate medical education- about educational leadership to support technology during the COVID-19 pandemic. In the first part of our paper we develop our conceptual framework of educational e-leadership during a crisis and then discuss our methodology. In the second part of our paper we follow Chorney and colleagues (2016) and interweave our experiences through conversational narrative. In the final section we discuss our findings and a re-imagined future with those findings.

\section{Educational Leadership and Educational E-Leadership}

Educational leadership includes both formal capacities of administration, as well as informal capacities with teacher leaders and coordinators (Kotter, 2001). Importantly, the capacities of leadership at all levels should attempt to organize conditions that foster high quality education that will generate improvements in learner outcomes (Leithwood et al., 2019). Some of these conditions may include an inclusive approach which solicits ideas from others and connects with other leaders to find ways of supporting colleagues and offer training (Breitkopf, 2018).

E-leadership extends the definition of leadership to include using information and communication technologies (ICTs) as a method of producing change in information, skills, beliefs, behaviour and performance (Avolio et al., 2014). Avolio et al. (2014) argue that while conditions of a general construct of effective leadership have been well established by research in practice, the roles and skill-set defining effective e-leadership are still incipient and broad. The adoption of digital skill-sets and the adaptation of required ICTs in e-leadership roles (Van Wart et al., 2017) is crucial to successful implementation of distance learning (Jameson, 2013; Preston 
et al., 2015). E-leadership requires those in the roles to manage challenges effectively in a digital space. Those who are poor at personally adopting required technologies will experience limited success as role-models and be ineffective managers of available resources (Sathithada \& Niramitchainont, 2019). Identification of good e-leadership, therefore, discriminates between those who are successful versus not successful in effective adoption of digital skill-sets and ICT implementation. The proximal and distal challenges of communication, technology adoption and technology skill development are unique to e-leadership (Van Wart et al., 2017). Often eleadership requires a hybrid of traditional-virtual operational leadership skills that mix ICTmediated and face-to-face communication, performance and behaviour (Van Wart et al., 2017; Van Wart et al., 2019). Leadership subsequently mentioned in this article will include a blended context between traditional educational leadership and educational e-leadership.

When supporting teachers during the liminal context of a crisis, educational leaders may use a distributional leadership approach (Spillane et al., 2015; Bolden, 2011; Murphy et al., 2009), and during technology implementation, educational e-leaders may use a democratic style of leadership to support greater agency and collaboration amongst members of their community (Shepherd-Jones \& Salisbury-Glennon, 2018).

During a time of crisis, abrupt transitions may allow for leaders to incorporate a distributed leadership framework in order to deal with a multitude of issues quickly, and may then be followed by a democratic leadership style to create stability after the initial crisis. In a distributed leadership framework, formal leaders are a part of a group of multiple individuals who may play a part in leadership and management work creating a leadership-dense organization (Spillane et al., 2015; Bolden, 2011; Murphy et al., 2009). During a crisis, formal leaders may use a distributed leadership framework to navigate the unexpected as a group rather than as an individual; the product of approaching the issues raised during a time of crisis, between both formal and informal leaders, is a distributed perspective (Spillane et al., 2015). A democratic leadership style when implementing technology incorporates methods of shared-decision making, opportunities for choice and selfdirection, ways to solicit feedback and to implement reasonable and valid suggestions, collaboration among community members, the building of relationships, an understanding of the value of individual members to the entire community, and explicit trust in individual and group competence (Shepherd-Jones \& Salisbury-Glennon, 2018). Democratic leadership styles applied to an e-learning environment would include leaders being committed to providing support for networking between staff and students, as well as to lifelong learning and self-e-learning based on technology and education (Chua \& Chua, 2017). When leadership focuses on the collective community through honesty, openness and benevolence, there is a higher degree by the community to accept the information and actions of the educational leaders to build trust (Anthony, 2011; Sutherland, 2017). Creating meaningful professional development and spaces of equity where community members can take risks in implementing technology (Anthony, 2011; Bates \& Morgan, 2018) are important ways democratic educational leaders can support the growth of their community when implementing technology. Technology integration in education requires leaders to change their roles, vision and day-to-day practices, as well as the strategies used within the institution (Chua \& Chua, 2017). EL can re-author themselves to have greater agency in various educational environments (Brewer et al., 2018). EL should also incorporate practical applications 
for building agency amongst their staff to promote a sense of security and confidence in the integration of technology into education.

\section{Educational Leadership and Implementing Technology During Times of Crisis}

The importance of educational leadership increases especially when a change system is being implemented (Kotter, 2001), like during a pandemic. There is limited research on leading during a time of crisis within the educational community because of the nature of pandemics. Some studies include the role of the educational leader in dealing with the educational community after a crisis, such as rebuilding school systems post-Hurricane Katrina in New Orleans (Beabout, 2010) and unanticipated deaths of students (Sutherland, 2017). Both these studies highlighted a need for EL to maintain a requisite stability and trust within their environments. In a time of crisis, an EL should consider that staff are living through the crisis as well and incorporate some consistency in order to help negate staff anxiety (Beabout, 2010; Sutherland, 2017).

Additionally, during a crisis in a school, trust for EL may also include benevolence, honesty, openness, reliability, and competence (Sutherland, 2017). Building trust as an educational leader is important for promoting cooperation and efficiency and minimizing anxiety and insecurity at all times, but particularly relevant during times of crisis (Seabright et al., 1992; Tarter et al., 1989; Tschannen-Moran \& Hoy, 2000). EL may build the foundations of a trusting environment prior to a crisis occurring. Importantly, this foundation may be the basis of overcoming barriers to the implementation of technology by staff to address a crisis, such as the COVID-19 educational closures. During a crisis, the sense of competence of an educational leader is elusive and may lead stakeholders, including teachers and parents, to believe that EL lack transparency and openness with information and communication (Sutherland, 2017).

\section{Barriers to Technology Implementation}

There are a number of reasons why EL may find it difficult to support technology integration. Both EL and members of the community may experience anxiety in attempting to integrate technology. Subsequently, support should move beyond traditional implementation techniques like those which presume existing teacher knowledge and experience in the area of development (Naidu \& Laxman, 2019; Vermeulen et al., 2016; Yuen \& Ma, 2008). There has been much research on barriers people experience when trying to support and implement new technology including lack of confidence, skills training and time (Naidu \& Laxman, 2019), ill-defined roles of those in leadership in how they will support integration, and an unclear vision of the change EL desire to see through technology implementation (Breitkopf, 2018). One of the greatest inhibitors to community members adapting to technology is ease of use (Vermeulen et al., 2016; Yuen \& Ma, 2008). Therefore, EL who seek to integrate technology in the most effective and uncomplicated manner should see a greater degree of participation by their staff.

EL should consider the particular barriers within their educational community and interact with and become knowledgeable of their own community. One way EL can become 
knowledgeable is to survey and discern their community members' attitudes toward integration and use of technology in their practice (Njiku et al., 2019; Schrum \& Levin, 2015). EL can also seek input from teachers to identify potential barriers and build a community of collective effort to improve programming delivery (Anthony, 2011; Breitkopf, 2018).

\section{Autoethnography}

An autoethnography is a qualitative method of inquiry that attempts to holistically collect data within the cultural context from the personal experience of the researcher (Ellis et al., 2011; Fraenkel et al., 2019). Chang and colleagues (2013) describe collaborative autoethnography as a

qualitative research method in which researchers work in community to collect their autobiographical materials and to analyze and interpret their data collectively to gain a meaningful understanding of sociocultural phenomenon reflected in their autobiographical data. (p. 23-24)

In autoethnographies, the researcher incorporates their personal experiences, retrospections and epiphanies within the cultural context of the environment in which they are observing and participating (Ellis et al., 2011). The autoethnographer treats data in an analytical, critical and interpretive lens (Chang, 2007) situating their cultural contextualization of experiences within a larger perspective (Fraenkel et al., 2019).

Autoethnography is a useful method to use during times of crisis because it allows for very recent topics to be supported by an area of research that has yet to incorporate quantifiable research. The self-reflective nature of autoethnographies also allows researchers to develop a more holistic perspective while in the field collecting data (Chang, 2007; Fraenkel et al., 2019). As such, we chose autoethnography as our methodology because it allowed us to gain a holistic understanding of our own leadership development embedded within the constantly changing climate of the crisis.

There have been detractors to autoethnographic research because of its potential for selfindulgence (e.g. Winkler, 2017). However, autoethnography is becoming a predominant tool available to researchers to learn more about human relationships with regards to enhancing cultural understanding. Autoethnography also has a greater potential to build understanding between disparate cultures and can help researchers understand themselves and others within a cultural context (Chang, 2007). Autoethnographers must acknowledge that their lives as part of data collection will be scrutinized and collect their data with the purpose of the connection to a broader cultural context (Winkler, 2017).

\section{METHODOLOGY}

We sought to interrogate our experiences as EL during the COVID-19 pandemic through authoethnographic data collection. Our group of participants included five graduate students in a directed studies course and one professor, all working in Ontario educational institutions. Of the 
five graduate students, two are elementary teachers with informal leadership roles, the third is a secondary school special education department head, the fourth is a secondary school administrator, and the fifth is a public healthcare education coordinator. The professor is in an administrative position in higher education.

As a group, we met eight times via videoconferencing software in May and June of 2020. During these meetings, we discussed, shared and reflected on our personal and professional experiences as EL during the COVID-19 pandemic. We also collected individual field notes to observe and highlight (Sullivan, 2000) the implementation and delivery of emergency remote teaching and learning in the context of our respective workplaces during the COVID-19 provincial closure in Ontario. These field notes and the recorded discussions provide the qualitative data used for analysis.

Each of us, from differing schools, school boards, and organizations, contributed our own personal reflections towards the compilation of a collaborative autoethnography. The act of reflection is an act of "synthesis: the creation of new ideas, perspectives, and possibilities" (Rose, 2013 , p. 8). As such, the sharing of our personal accounts is a remembering of the past, a consideration of the future, and a synthesis of what both mean for the present situation (Pinar, 1975; Wang, 2010).

\section{Autoethnographies}

The provincial shutdown experience for each of us presented its own set of challenges and successes. We each had to overcome different obstacles. However, we all discovered and developed greater leadership qualities as we sought to strategize and overcome those obstacles.

At the Start. One of the early consequences on education from the COVID-19 crisis was the uncertainty of continuing the delivery of education. The provincial closures meant the temporary suspension of educational programs in the K-12 system, as well as the healthcare system. All of our leadership roles in education were directly impacted by the introduction of the pandemic closures in Ontario. The sudden announcement of a province-wide educational shutdown due to the COVID-19 pandemic created an environment of questions about what was to come and actions to support the new online delivery system:

Martina. Upon hearing the announcement that schools would be closed for two weeks, my initial reaction was to celebrate the extra holiday - teachers surrounding me in the parking lot were thrilled at the prospect of an extended break, and students were feeling much the same. It had been a time of unrest and uncertainty for Ontario elementary schools, as teachers had been in a strike position for months leading up to that moment. Before COVID-19, I used to think to myself "I wish I could teach from home!" and "I could easily swap my courses into a flipped model!" Initially my mindset upon hearing we would begin teaching from home was that technology-assisted distance learning would be an exciting prospect, and one that I would enjoy. 
Sonya. I heard that Ontario schools would be closed due to the COVID-19 pandemic over the radio (Varley, 2020). As a secondary school vice principal in Ontario I had a number of questions: Does this mean no schooling at all? How and what will we communicate with staff? Students? Parents? I received anxious messages from staff who were questioning what was happening and how their teaching roles would change. Ontario ("Ontario unveils details of learnat-home program," 2020) announced education would be delivered while maintaining quarantine and social distancing mandates. We had little detail, but still, our school board and school administration began to strategize how distance learning would work. We had to take into account that the Board, and therefore the school administration, often communicated with staff from a deficit of information from the Ministry of Education. Questions from staff could often not be answered because we did not have the ability to make decisions based on our school community as we normally would. This added to the anxiety of the staff as well as school leadership, including me.

Lindy. As a hospital education coordinator and healthcare worker, I followed the development of the COVID-19 pandemic very closely. On March 11th, the World Health Organization declared COVID-19 as a pandemic. While some general information on the pandemic had been disseminated from hospital leadership, I did not know what this meant for my department or my role specifically. On March 13th, 2020, my manager told me I was to begin working from home indefinitely starting the next week. That same day, I received a flood of placement cancellations for medical students, residents and fellows who were scheduled to rotate through the hospital in the coming months, notification that all on-site teaching rounds were cancelled for the next 16 weeks, as well as the cancellation of all the upcoming courses for the department's education centre. It felt like within a day, my hospital's education program had been completely cancelled.

Michael. I provide departmental and school-wide leadership as an assistant curriculum leader of Special Education, a collegial leadership role (McGrath et al., 2016) that I perform in addition to my teaching duties. As the first full week after our March Break came and went without any lessons, meetings, or extracurriculars for our students, the feeling of uncertainty was intense. I felt a sudden lack of control over many things, so I focused on what I could still influence. I sent a video message with words of encouragement for my colleagues. Every person I sent the video to replied back with updates on their family and how they were coping. In the face of so much uncertainty I felt assured that, together, we would be able to get through whatever the rest of the school year looked like.

Seshi. At the start of distance learning due to the pandemic I remember feeling absolutely lost how we were going to manage something that resembled our regular school life. The stress of creating an online learning experience was on top of the already existing stress of being a new teacher and having to learn aspects of teaching that are gained by several years of experience in the field. I found it difficult to find reliable sources on what the next steps of our teaching practice might look like during this crisis. It was difficult to predict what decisions would be made by the school board and Ministry about how learning would take place which made the hiatus of waiting 
for next steps a difficult process. However, as the weeks progressed, I felt comfortable with some of the online teaching and learning strategies, and appreciated how they informed my axiological and philosophical ideals in teaching in the online environment.

Beginning to Transition. All of us experienced little to no personal techno-anxiety (Muñoz et al., 2016) due to our pre-existing skill sets and self-efficacy (Holden \& Rada, 2011). However, feelings of techno-anxiety experienced by colleagues led to the redefinition of our roles, including for two of us, becoming informal leaders in our educational units. This development involved some tough decision-making and risk-taking, which consequently resulted in the enhancement of our leadership agency.

Sonya. Our school system leaders communicated that learning would be fully online, and teachers in our school board could choose between three different online platforms - Edsby, Office 365 and D2L/Brightspace. Planning for distance education was complicated and had to be done in a very short period of time. First, we had to ensure that staff had access to the appropriate technology, which was complicated by the fact that some staff left their laptops and other resources at school as they left for the March Break prior to the school closure announcement. The school was completely inaccessible for retrieving technology and supplies due to health and safety concerns. Second, having worked in four different secondary schools, I was well aware of the potential existence of a cohort of teachers who might exhibit 'tech anxiety '(Naidu \& Laxman, 2019) that would need to be supported through group and individual training. Planning required a great deal of self-reflection as I implemented methodologies to support teachers supporting students while attempting to fill the technological gaps of both students and staff. Just as with a class of students, each staff member was at a different stage of comfort with technology and teaching curriculum through distance learning. As an educational leader, I realized that I would have very individual approaches to staff concerns and issues, but I also attempted to work with groups of teachers regularly in order to address common concerns. Supporting staff individually or in a group proved to be incredibly beneficial for assuaging staff anxiety, although it did increase my workload significantly during the school closures, which, in turn affected my own general mental health and wellness.

Seshi. Using self-talk, I argued myself into two possible routes: I could play it safe with my own teaching and learning during this turbulent time; or I could take the opportunity to lead a few colleagues in a series of professional development sessions. This way I could help improve my colleagues' use of online platforms, such as D2L's Brightspace and Google Classroom. I decided to choose the second option so I could develop my inquiry (Stevens et al., 2016) for pedagogy. My decision led to a hopeful group of colleagues willing to try new roles in their teaching practice including: reevaluating their own professional learning, revisiting their teacher education, and implementing new learning techniques from our learning community. While it was a mutual understanding that we would be using online methods of learning, access to technology and the levels of understanding of using the tools for online teaching were vastly different from colleague to colleague. Gathering the information about the various levels of their comfort with 
technology and starting to gather data about the variables in play during this time was a strenuous and time-consuming process.

Lindy. The hospital had approved MS Teams for online collaboration and teaching rounds were to be moved online. Previously these rounds were held completely in-person across a set of large seminar rooms, so it was going to be a challenge migrating both staff doctors and trainees to this new online platform. While I would be organizing and scheduling the virtual meetings, all teaching staff would need to learn how to present on MS Teams - how to share their screens, use the microphone, camera, pointer, as well as the interactive functions such as the chatbox and "raise hand" functions. I reached out to all presenting staff and offered to hold individual MS Teams tutorials with anyone who desired. Responses soon came trickling in - an administrative coordinator, a supervisor and many of the doctors, including some of our most senior and respected faculty reached out for assistance. While many seemed at first unsure and nervous about using new technology (some more than others), everyone seemed to catch on quickly. Improving their knowledge on information and communication technologies, in this case MS Teams, appeared to reduce techno-anxiety in staff (e.g. Muñoz et al., 2016). Everyone seemed to understand distancelearning was necessary to continue education under the current circumstances.

Michael. When schools restarted virtually after a week-long closure, the majority of my time was initially dedicated to leading colleagues in my department in the process of learning how to teach effectively in a remote virtual environment. Some of my colleagues initially struggled with the basics of cloud storage, or with navigating Google Classroom and integrating other Google applications within that environment. Meanwhile I shared more advanced tips with other teachers, such as how to refine slideshow presentations with voice-over recordings. I organized weekly virtual department meetings which enabled child \& youth workers, educational assistants, and teachers to work collaboratively to identify and implement appropriate supports and resources for the families of students with disabilities who struggled with remote learning or lacked adequate access to technology.

Martina. Most of the "distance learning" implementation was left to teachers to figure out. With very basic guidance from the school board, we were required to plan with division leaders and grade partners to make decisions on how we would connect with students and establish an online learning environment. In my division, we are fortunate to have an existing one-to-one Chromebook model in place - all of my students already had their own laptop device, and they were already completing their classwork in Google Classroom before the pandemic-forced distance learning situation. The four core subject teachers with whom I work most closely already had most of the tools required to begin distance learning quickly and easily, and as such there were few barriers to transitioning to online learning. Something we knew we needed to focus on was maintaining a positive connection with our students to combat anxiety and fatigue associated with online learning (Minahan, 2020). 
Growth. The experience of leading during the pandemic closures created a number of opportunities for us to trial supports for staff and colleagues that addressed our most processing needs: community and individual wellness and barriers to technology uptake.

Seshi. My role as an informal leader in technology within our school would not have been as apparent to me without this pandemic as it has become now, during the pandemic. The way our online community came together felt like we tapped into Harasim's (1996) online collaborative theory and a true intellectual convergence occurred when implementing new online learning methods. The online community helped some teachers who felt nervous with using technology while implementing distance learning to learn new skills and pedagogical methods through professional development sessions. Adding to this role, I also helped organize community events to start online clubs where school staff could lead the community members of our school in activities such as baking, yoga, exercise, coding and more.

Michael. Throughout the period of emergency remote teaching and learning, and particularly in the first month, providing instructional and technological leadership (Flanagan \& Jacobsen, 2003) and emotional labour (Held \& McKimm, 2012) were the most important roles I played for my colleagues and for the students and families we serve. As the weeks and months wore on, paradoxically I felt a high degree of self-efficacy, while at the same time I experienced a continually decreasing sense of agency. I believe I possessed the skills necessary to lead remotely, but I still did not feel I could have the same impact as a leader by phone, email, or video conference, as compared to when I was able to sit down and interact with others in person. I felt a dichotomy of emotions in my leadership role during the pandemic. On the one hand, I took action and mobilized myself and others to support some of our neediest students. On the other hand, despite my best intentions and efforts to lead my colleagues and my students with disabilities through the crisis, as an agent of the education system I felt complicit in the widening achievement gaps as less privileged students fell behind their peers during the pandemic.

Lindy. As education coordinator, I manage the onboarding of new trainees every July. Before the pandemic I had given in-person orientations and had a "physical" open-door policy. During the pandemic, I found myself voluntarily working longer hours, as I tried to maintain a "virtual" open-door policy and plan for virtual orientations. To support leaders and teams in our department I had to leverage my pre-existing technology skill-sets; I had previously learned how to use Adobe Connect in my Masters of Education program, which included more complex but similar features to MS Teams. Luckily this allowed me to learn how to use MS Teams quickly, so that I could personally use it for my own work and also share this knowledge and help other staff. I began to take on an informal role in e-leadership (Chua \& Chua, 2017; Jameson, 2013). Although tiresome, I found my role to be incredibly rewarding as those around me expressed gratitude. I have great respect for the staff and faculty in my department; I found it extremely rewarding to be able to teach and equip them with these new tools and was touched by how receptive they were to my instruction. No one pushed back on this new approach; for the foreseeable future, this was our new normal. 
Martina. As a member of the school improvement team, the divisional chair, and an educational technology leader, I aim to be effective at collaborating with colleagues and providing guidance where possible. During the pandemic stay-at-home period, it was difficult to provide leadership in the usual capacity. I felt a transition in my own leadership position as a facilitator of the online learning environment for our team and the students. My technology leader partner took the lead on assisting the primary and junior teachers to create Google Sites to share lesson plans while I worked with the intermediate division teachers in creating a collaborative "hub" website. This website enabled students to check in daily and provided a virtual "homeroom" which helped most students feel connected with their teachers. We were not participating in synchronous lessons because many staff felt that synchronous lessons posed an equity issue because students had different levels of consistency in access to technology. Many households in our community were working with shared spaces and devices, and many of our students were responsible for caring for younger siblings or elderly family members during the school closure. Students voiced concerns about being able to attend live lessons at a specific time, as did parents. Some staff were also managing their own children's distance learning and were not able to operate live meetings online without distraction. There were more benefits to allowing students and teachers to post and review work or feedback when they were able to do so, as they felt they could access the online learning environment at a time and pace that suited them.

Sonya. Our administrative team held multiple staff meetings in an attempt to be open, transparent and build trust during this historical moment in our lives (Sutherland, 2017). The messaging of meetings included emphasizing a need to create an asynchronous streamlined curriculum and to keep assessment as primarily formative rather than evaluative, particularly in the first few weeks of online teaching. We also created a network of communication channels (e.g. online, over the phone, and socially-distanced face-to-face meetings) for in order to prevent feelings of isolation during the pandemic closures (Anthony, 2011; Sutherland, 2017). I also decided to lead "Tech@Ten" sessions with the goal to support staff comfort with technology in a safe and judgement-free environment, showing through modelling and my own learning how to approach this new educational environment (Bates \& Morgan, 2018). Staff inquiries about technology that I was unfamiliar with was an opportunity for me to co-learn that technology, which was beneficial to my own development. I also learned that the emotional and professional support using skills based on sympathy, understanding and a sense of humour aided significantly in dispelling pressure on the staff, as well as the pressure I placed on myself.

\section{DISCUSSION}

COVID-19 caused a tumult in the educational world. Everyone grew and changed in some way through their roles in education. Many who did not necessarily consider themselves educators before, became educators out of necessity, and those who were already educators had to rethink the way they taught and the way they viewed technology. As leaders, we too were changed through our roles in education. Some of us who did not necessarily consider ourselves leaders before the pandemic, became leaders out of necessity. And the rest of us who were already leaders had to 
reconstruct the way we lead and viewed technology. Our change came about because of our support of our educators' changes.

Leithwood and colleagues (2019) discuss the purposeful execution of leadership at all levels to support technology. At the same time as being purposeful, our leadership roles were evolving because of our daily changing needs caused by the pandemic. In each of our situations, our leadership roles developed into something different because of the technology aspect of our leadership. This evolution remained true whether our leadership was a formal role (i.e. we had leadership roles before the pandemic), or informal (i.e. we developed into leaders because of the pandemic). Both as formal and informal leaders, we were each faced with a different set of barriers to overcome, ranging from lack of information and directives to staff struggling with learning the new technologies. Because of the restrictions brought on by the pandemic, we embraced our leadership roles by moving beyond traditional implementation techniques (Naidu \& Laxman, 2019; Vermeulen et al., 2016; Yuen \& Ma, 2008). To handle these barriers, we embraced a democratic leadership style (Shepherd-Jones \& Salisbury-Glennon, 2018), which heavily focussed on honest and open communication between staff and colleagues, while providing skills and techniques to support their professional development and self e-learning. This approach allowed us to overcome the different barriers that arose in each of our particular scenarios.

At the beginning of the transition to online learning we experienced a range of emotions. In each case we felt a lack of agency - we could not anticipate or plan for the changes in how we were to teach and at what capacity. We did not have the luxury to concentrate on our own feelings of a lack of agency, as those around us turned to us for support as they moved into uncomfortable technology spaces (Muñoz et al., 2016). Everything we did centred around the support of our colleagues and teams in helping to support and develop their agency and sense of efficacy around technology (Holden \& Rada, 2011). We found that through creating a sense of agency for others we developed our own sense of agency. This collaborative revelation about the importance of creating agency for ourselves and others was important. We were reminded that our capacity for agentic change is continuous. This effectively helped create feedback loops where our roles as EL directly influenced a sense of agency for ourselves and others (Hargreaves \& Ainscow, 2015). Secondly, we found that a sense of agency for us as EL was important for there to be active changes in policy and practice (Frost, 2006). This is important during a crisis (Sutherland, 2017). Like Brewer and colleagues (2018) we found that EL can encourage change in others through a sense of agency, which then propels purposeful and collaborative practice in education.

Similar to the findings of Sutanto (2011), we engaged more frequently in mediating behaviours during online collaboration that proved to be beneficial to the success of our teams. We supported our staff and colleagues personally as well as professionally by providing support through stressful situations and guidance on new online practices and expectations. We engaged in emergent leadership in small groups (Comfort \& Okada, 2013), working with their teams to achieve their goals; this may have come to fruition due to the lack of direction from higher organizations. We developed our educational e-leadership through evolving our interpretations of current educational practices, understanding our influence on their group members and taking on 
new perspectives of education. We also developed through our support of their community by supporting our staff and colleagues in their development of learning new virtual skills and navigating new online platforms (Lewin et al., 2010).

During a crisis EL must respond to events in addition to the resulting outpour of emotions and consequences from that event, maintaining trust through honesty, reliability, and competence (Sutherland, 2017). Effective EL address and appropriately work through the impacts and implications through short and long-term crises. In our case, we had to deal with numerous barriers to technology implementation and work to develop others 'sense of agency, while also developing our own.

\section{CONCLUSION}

Leading through a time of crisis is complex. Our experiences supporting each other, as each of us supported others, provided us with a unique perspective and an opportunity to learn and grow as leaders. We also had the opportunity to discuss an imagined future for education and leadership in education in the aftermath of a global pandemic. We have explored what we learned above. The question remains, how can we take this learning and our growth, and re-envision what technology can be for education now that we and our surroundings have all changed so much. What would leadership look like if the goal was the constant state of growth and change that we experienced during the COVID-19 pandemic?

We had to look deep within ourselves to respond to the crises we encountered in our leadership. One singular leadership method or one way to respond to and recover from an event was neither an ideal or realistic approach for us. Although there can be a definitive start and end to a crisis, leadership does not necessarily have a beginning and end.

Although predicting a crisis and its implicated intricacies is reasonably impossible, building the skills necessary to support an educational community prior to a crisis may be possible. In the meantime, EL should continue to focus on building agency amongst their staff to promote a sense of security and confidence in integration of technology into education, so that their professional development continues. This development will better prepare educators and give them the confidence to effectively address the implications presented through short and long-term crises. While many barriers exist to a successful transition, EL can provide the trustworthy and knowledgeable support and guidance required in order to instil confidence and facilitate the development of their colleagues and staff. Our hope for the future is that if another crisis occurs that requires a quick shift in education, EL - including ourselves, will be ready and able to achieve this successfully. 


\section{REFERENCES}

Anthony, A. B. (2011). Activity theory as a framework for investigating district-classroom system interactions and their influences on technology integration. Journal of Research on Technology in Education, 44(4), 335-356. https://doi.org/10.1080/15391523.2012.10782594

Avolio, B. J., Sosik, J. J., Kahai, S. S., \& Baker, B. (2014). E-leadership: Re-examining transformations in leadership source and transmission. The Leadership Quarterly, 25(1), 105-131.

Bass, B. M. (2008). Bass and Stodill s handbook of leadership: A survey of theory and research (4th ed.). Free Press.

Bates, C. C., \& Morgan, D. N. (2018). Literacy leadership: The importance of soft skills. The Reading Teacher, 72(3), 412-415. https://doi.org/10.1002/trtr.1755

Beabout, B. R. (2010). Leadership for change in the educational wild west of post-Katrina New Orleans. Journal of Educational Change, 11(4), 403-424. https://doi.org/10.1007/s10833-010-9136-8

Bolden, R. (2011). Distributed leadership in organizations: A review of theory and research. International Journal of Management Reviews, 13(3), 251-269. https://doiorg.uproxy.library.dc-uoit.ca/10.1111/j.1468-2370.2011.00306.x

Breitkopf, M. (2018). But this is how we have always done it: Overcoming resistance to change in the quest to support distance learners. Journal of Library \& Information Services in Distance Learning, 12(3-4), 148-164. https://doi.org/10.1080/1533290x.2018.1498627

Brewer, C., Okilwa, N., \& Duarte, B. (2018). Context and agency in educational leadership: framework for study. International Journal of Leadership in Education, 23(3), 330-354. https://doi.org/10.1080/13603124.2018.1529824

Chang, H. (2007). Autoethnography: Raising cultural consciousness of self and others. Methodological Developments in Ethnography Studies in Educational Ethnography, 12, 207-221. doi:10.1016/s1529-210x(06)12012-4

Chang, H. (2013). Individual and Collaborative Autoethnography as Method: A Social Scientist's Perspective. In S. H. Jones, T. E. Adams \& C. Ellis (Eds.), Handbook of Autoethnography (pp. 107-119). Walnut Creek, CA: Left Coast Press.

Chorney, S., Noble, T., Ruttenberg-Rozen, R., \& Phakeng, M. S. (2016). Sharing space with the other to discuss mathematics education and social justice. For the Learning of Mathematics, 36(3), 46-49.

Chua, Y. P., \& Chua, Y. P. (2017). How are e-leadership practices in implementing a school virtual learning environment enhanced? A grounded model study. Computers \& Education, 109, 109-121. https://doi.org/10.1016/j.compedu.2017.02.012

Comfort, L., \& Okada, A. (2013). Emergent leadership in extreme events: A knowledge commons for sustainable communities. International Review of Public Administration, $18,61-77$.

Ellis, C., Adams, T. E., \& Bochner, A. P. (2011). Autoethnography: An overview. Forum: Qualitative Social Research, 12(1), 1-18. 
Fawns, T., Jones, D., \& Aitken, G. (2020). Challenging assumptions about "moving online" in response to COVID-19, and some practical advice. MedEdPublish, 9(1). https://doi.org/10.15694/mep.2020.000083.1

Flanagan, L., \& Jacobsen, M. (2003). Technology leadership for the twenty-first century principal. Journal of Educational Administration, 41(2), 124-142. https://doi.org/10.1108/09578230310464648

Fraenkel, J. R., Wallen, N. E., \& Hyun, H. H. (2019). How to design and evaluate research in education. McGraw Hill Education.

Frost, D. (2006). The concept of 'agency 'in leadership for learning. Leading and Managing, 12(2), 19-28.

Harasim, L. (1996). Online education. In T. M. Harrison \& T. Stephen (Eds.), Computer networking and scholarly communication in the twenty-first-century university, (pp. 20321). New York, NY; State University of New York Press.

Hargreaves, A., \& Ainscow, M. (2015). The top and bottom of leadership and change. Phi Delta Kappan, 97(3), 42-48. doi: 10.1177/0031721715614828

Held, S. \& McKimm, J. (2012). Emotional intelligence, emotional labour and affective leadership. In M. Preedy, N. Bennett \& C. Wise (Eds.), Published in Association with the Open University: Educational leadership: Context, strategy and collaboration (pp. 5264). London: SAGE Publications Ltd doi: 10.4135/9781473915244.n5

Holden, H., \& Rada, R. (2011). Understanding the influence of perceived usability and technology self-efficacy on teachers 'technology acceptance. Journal of Research on Technology in Education, 43(4), 343-367.

Hung, M. (2016). Teacher readiness for online learning: Scale development and teacher perceptions. Computers \& Education, 94, 120-133. https://doi.org/10.1016/j.compedu.2015.11.012

Jameson, J. (2013). e-Leadership in higher education: The fifth "age" of educational technology research. British Journal of Educational Technology, 44(6), 889-915. https://doi.org/10.1111/bjet.12103

Kotter, J. P. (2001). What leaders really do. Harvard Business School Pub. Corp.

Leithwood, K., Harris, A., \& Hopkins, D. (2019). Seven strong claims about successful school leadership revisited. School Leadership \& Management, 40(1), 5-22. https://doi.org/10.1080/13632434.2019.1596077

Lewin, B., Hlupic, V., \& Walton, C. (2010). Emergent Leadership. Leadership Excellence, 27(3), 17.

Mcgrath, C., Barman, L., Stenfors-Hayes, T., Roxå, T., Silén, C., \& Laksov, K. B. (2016). The ebb and flow of educational change: Change agents as negotiators of change. Teaching \& Learning Inquiry: The ISSOTL Journal, 4(2). https://doi.org/10.20343/teachlearninqu.4.2.9

Minahan, J. (2020). Maintaining connections, reducing anxiety while school is closed. Educational Leadership, 77, 22-27. http://www.ascd.org/publications/educationalleadership/summer20/vol77/num10/Maintaining-Connections,-Reducing-Anxiety-WhileSchool-Is-Closed.aspx 
Muñoz, O.R., Penalba, F.A., Sánchez, J.F., \& Santos, O. C. (2016). Reducing techno-anxiety in high school teachers by improving their ICT problem-solving skills. Behaviour \& Information Technology, 36(3), 255-268. https://doi.org/10.1080/0144929x.2016.1221462

Murphy, J., Smylie, M., Mayrowetz, D., \& Louis, K. S. (2009). The role of the principal in fostering the development of distributed leadership. School Leadership \& Management, 29(2), 181-214. DOI: 10.1080/13632430902775699

Naidu, S. S., \& Laxman, K. K. (2019). Factors inhibiting teachers 'embracing e-learning in secondary education: a literature review. Asian Journal of Distance Education, 14(2), $124-143$.

Northouse, P. G. (2013). Leadership: Theory and practice (6th ed.). Sagee.

Njiku, J., Maniraho, J. F., \& Mutarutinya, V. (2019). Understanding teachers 'attitude towards computer technology integration in education: A review of literature. Education and Information Technologies, 24(5), 3041-3052. https://doi.org/10.1007/s10639-019-09917-z

Preston, J. P., Moffatt, L., Wiebe, S., McAuley, A., Campbell, B., \& Gabriel, M. (2015). The use of technology in Prince Edward Island (Canada) high schools: Perceptions of school leaders. Educational Management Administration \& Leadership, 43(6), 989-1005.

Pinar, W. (1975, April). The method of "currere." The annual meeting of the American Research Association, Washington D.C.

Rose, E. (2013). On reflection: An essay on technology, education, and the status of thought in the 21st century. Canadian Scholars 'Press.

Sathithada, K., \& Niramitchainont, P. (2019). Scenarios of a sustainable e-leadership for Thai higher educational institution leaders in 2027. Discourse \& Communication for Sustainable Education, 10(1), 81-90. https://doi-org.uproxy.library.dcuoit.ca/10.2478/dcse-2019-0007

Schrum, L., \& Levin, B. B. (2015). Educational technologies and twenty-first century leadership for learning. International Journal of Leadership in Education, 19(1), 17-39. https://doi.org/10.1080/13603124.2015.1096078

Seabright, M. A., Levinthal, D. A., \& Fichman, M. (1992). Role of individual attachments in the dissolution of interorganizational relationships. Academy of Management Journal, 35(1), 122-160. https://doi.org/10.2307/256475

Shepherd-Jones, A. R., \& Salisbury-Glennon, J. D. (2018). Perceptions matter: The correlation between teacher motivation and principal leadership styles. Journal of Research in Education, 28(2), 93-131.

Spillane, J. P., Harris, A., Jones, M., \& Mertz, K. (2015). Opportunities and challenges for taking a distributed perspective: Novice school principals 'emerging sense of their new position. British Educational Research Journal, 41(6), 1068-1085. DOI: 10.1002/berj.3166

Stevens, D. M., Brydon-Miller, M., \& Raider-Roth, M. (2016). Structured ethical reflection in practitioner inquiry: Theory, pedagogy, and practice. The Educational Forum, 80(4), 430-443. https://doi.org/10.1080/00131725.2016.1206160 
Sullivan, A. M. (2000). Voices inside schools - Notes from a marine biologist's daughter: On the art and science of attention. Harvard Educational Review, 70(2), 211-227. https://doi.org/10.17763/haer.70.2.x8601x6tn8p256wk

Sutanto, J. (2011). Emergent leadership in virtual collaboration settings: A social network analysis approach. Long Range Planning., 44(5/6), 421-439.

Sutherland, I.E. (2017), Learning and growing: Trust, leadership, and response to crisis. Journal of Educational Administration, 55(1), 2-17. https://doi.org/10.1108/JEA-10-2015-0097

Tarter, C. J., Bliss, J. R., \& Hoy, W. K. (1989). School characteristics and faculty trust in secondary schools. Educational Administration Quarterly, 25(3), 294-308. https://doi.org/10.1177/0013161x89025003005

Tschannen-Moran, M., \& Hoy, W. K. (2000). A multidisciplinary analysis of the nature, meaning, and measurement of trust. Review of Educational Research, 70(4), 547-593. https://doi.org/10.3102/00346543070004547

Van Wart, M., Roman, A., Wang, X., \& Liu, C. (2017). Integrating ICT adoption issues into (e)leadership theory. Telematics \& Informatics, 34(5), 527-537. https://doiorg.uproxy.library.dc-uoit.ca/10.1016/j.tele.2016.11.003

Van Wart, M., Roman, A., Wang, X., \& Liu, C. (2019). Operationalizing the definition of eleadership: Identifying the elements of e-leadership. International Review of Administrative Sciences, 85, 80-97.

Varley, K. (2020, March 12). Ontario schools closing until April 5. iHeart Radio. https://www.iheartradio.ca/am800/news/ontario-schools-closing-until-april-51.10700763 .

Vermeulen, M., Kreijns, K., Buuren, H. V., \& Acker, F. V. (2016). The role of transformative leadership, ICT-infrastructure and learning climate in teachers' use of digital learning materials during their classes. British Journal of Educational Technology, 48(6), 14271440. https://doi.org/10.1111/bjet.12478

Wang, H. (2010). The temporality of currere, change, and teacher education. Pedagogies: An International Journal, 5(4), 275-285. https://doi.org/10.1080/1554480x.2010.509469

Winkler, I. (2017). Doing autoethnography: Facing challenges, taking choices, accepting responsibilities. Qualitative Inquiry, 24(4), 236-247. https://doi.org/10.1177/1077800417728956

Yuen, A. H. K., \& Ma, W. W. K. (2008). Exploring teacher acceptance of e-learning technology. Asia-Pacific Journal of Teacher Education, 36(3), 229-243. https://doi.org/10.1080/13598660802232779 


\section{Authors}

Lindy Hudson is a hospital education coordinator in Ontario. Her research interests lie in adult and continuing education in the healthcare sector, with a focus on the utilization of current and advancing technologies for the purposes of teaching and learning. Lindy completed an Honours Bachelor of Arts degree specializing in Bioethics at the University of Toronto and at present is completing her Master of Education at Ontario Tech University.

Seshaanth Mahendrarajah is an intermediate teacher in Toronto, Ontario. Seshaanth is currently a student in the Master of Education program at Ontario Tech University with a focus on digital technology. He also holds a Bachelor's Degree in Education from UOIT (2018) as well as a Bachelor's Degree in Science from the University of Western Ontario (2016). He has particular research interests in helping students overcome barriers that impact their learning, closing the achievement gap, and promoting equity for all students.

Martina Walton is an elementary teacher in Oshawa, Ontario. She teaches intermediate students English and Social Studies. Martina studied English Literature at Western University and Education at the University of Alberta. During her undergraduate degrees, Martina enlisted as a military reserve officer, completing two years of training before moving to France for an international university exchange program at the Universite d'Aix-en-Provence. She is continuing in her pursuit of higher education by completing her Masters of Education at Ontario Tech University. She is interested in curriculum development and reform in Ontario.

Michael James Pascaris is an Ontario Certified Teacher currently teaching and leading in the Special Education department of a secondary school in Toronto, Canada. He is a graduate student in the Master of Education program at Ontario Tech University, where he is focusing on leadership and technology in K-12 education. He obtained his Bachelor of Education degree at OISE after completing a Bachelor of Science degree at York University. Michael previously authored an article in Education Canada magazine titled "The Power of Paperless" that described how teachers can use Google apps to support students with special needs in inclusive classrooms.

Sonya Melim is currently a principal of a virtual secondary school in Ontario. At the time of this paper, she was a vice principal of an Ontario secondary school. Sonya is a master's program student in the Faculty of Education at Ontario Tech University. She holds a Bachelor of Education from Queen's University and a Bachelor of Arts, Honours from Queen's University. She has research interests on the role of leadership in education with the implementation of technology, with additional interest in the use and integration of mobile technology, social and cultural contexts of education, and assessment and evaluation.

Dr. Robyn Ruttenberg-Rozen is an Assistant Professor at Ontario Tech University in Oshawa, Ontario. Robyn is also the director of the IDEASS lab where, together with her colleagues and students, she studies innovation, digital spaces, equity and access in STEAM.

\section{Corresponding Author:}

Lindy Hudson

Lindy.Hudson@ontariotechu.net 